\title{
Identification and characterisation of short chain rhamnolipid production in a previously uninvestigated, non-pathogenic marine pseudomonad
}

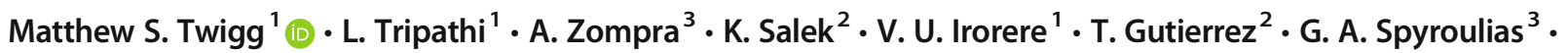 \\ R. Marchant ${ }^{1} \cdot$ I. M. Banat ${ }^{1}$
}

Received: 16 May 2018 / Revised: 25 June 2018 / Accepted: 26 June 2018 / Published online: 10 July 2018

(C) The Author(s) 2018

\begin{abstract}
This study aimed to identify and characterise biosurfactant compounds produced by bacteria associated with a marine eukaryotic phytoplankton bloom. One strain, designated MCTG214(3b1), was isolated by enrichment with polycyclic aromatic hydrocarbons and based on $16 \mathrm{~S}$ rDNA, and gyrB sequencing was found to belong to the genus Pseudomonas, however not related to $P$. aeruginosa. Cell-free supernatant samples of strain MCTG214(3b1) at stationary phase showed significant reductions in surface tension. HPLC-MS and NMR analysis of these samples indicated the presence of five different rhamnolipid (RL) congeners. Dirhamnolipids accounted for $87 \%$ relative abundance and all congeners possessed fatty acid moieties consisting of $8-12$ carbons. PCR screening of strain MCTG214(3b1) DNA revealed homologues to the $P$. aeruginosa RL synthesis genes rhlA and rhlB; however, no rhlC homologue was identified. Using the Galleria mellonella larvae model, strain MCTG214(3b1) was demonstrated to be far less pathogenic than P. aeruginosa. This study identifies for the first time a significantly high level of synthesis of short chain di-rhamnolipids by a non-pathogenic marine Pseudomonas species. We postulate that RL synthesis in Pseudomonas sp. MCTG214(3b1) is carried out by enzymes expressed from $r h l A / B$ homologues similar to those of $P$. aeruginosa; however, a lack of rhlC potentially indicates the presence of a second novel rhamnosyltransferase responsible for the di-rhamnolipid congeners identified by HPLC-MS.
\end{abstract}

Keywords Biosurfactant $\cdot$ Rhamnolipid $\cdot$ Pseudomonas $\cdot$ Marine bacteria $\cdot$ Non-pathogenic

\section{Introduction}

Biosurfactants are amphipathic compounds comprising hydrophobic and hydrophilic moieties that confer on them the ability to interface with non-soluble and soluble substances.

Electronic supplementary material The online version of this article (https://doi.org/10.1007/s00253-018-9202-3) contains supplementary material, which is available to authorized users.

Matthew S. Twigg

m.twigg@ulster.ac.uk

1 School of Biomedical Sciences, Ulster University, Coleraine, Northern Ireland BT52 1SA, UK

2 Institute of Mechanical, Process and Energy Engineering, School of Engineering and Physical Sciences, Heriot-Watt University, Edinburgh EH14 4AS, UK

3 Department of Pharmacy, University of Patras, 26504 Patras, Greece
These compounds have been shown to be synthesised by a wide variety of microbial taxa, function to reduce tension at interfacial surfaces and have many industrial applications (Desai and Banat 1997; Banat et al. 2010). The most ubiquitous group of bacterial synthesised biosurfactants is glycolipids of which the best characterised class is the rhamnolipids (RLs) (Desai and Banat 1997; AbdelMawgoud et al. 2010). RLs are composed of either one or two rhamnose monosaccharides covalently bonded with up to two 3-(hydroxyalkanoyloxy)alkanoic acid (HAA) fatty acid tails ranging between 8 and 16 carbons in length (Abdel-Mawgoud et al. 2010). Bacterial RL biosynthesis was first elucidated in the Gram negative, opportunistic pathogen Pseudomonas aeruginosa (Bergstrom et al. 1946; Jarvis and Johnson 1949; Rudden et al. 2015). Although $P$. aeruginosa can synthesise a range of RL congeners, di-rhamnolipids are the most abundant, with RhaRha- $\mathrm{C}_{10}-\mathrm{C}_{10}$ predominating (Rudden et al. 2015). Monorhamnolipids are also produced by $P$. aeruginosa as 
precursors to di-rhamnolipid; strains only synthesising mono-rhamnolipids are rare (Déziel et al. 1999; Rudden et al. 2015). RL synthesis is achieved using three separate enzymes: RhlA, responsible for the synthesis of the fatty acid dimer precursor moieties (HAA); RhlB, a rhamnosyltransferase enzyme which conjugates HAA to dTDP-L-rhamnose to form mono-rhamnolipid and RhlC, a second rhamnosyltransferase enzyme that utilises mono-rhamnolipid as substrate adding a second dTDP-Lrhamnose to form di-rhamnolipid (Ochsner et al. 1994; Rahim et al. 2001; Deziel et al. 2003). These enzymes are expressed from the genes $r h l A$ and $r h l B$, located on a single operon alongside an AHL-mediated quorum sensing system $(r h l R I)$ and $r h l C$, which is located approx. $2.5 \mathrm{Mb}$ downstream of the $r h l$ operon (Ochsner et al. 1994).

The global production of surfactant compounds for industrial use was estimated at 13 million tonnes per annum (Marchant and Banat 2012), with the majority of these compounds derived from organic chemical synthesis using petrochemicals. Petrochemical-derived surfactant production is detrimental for two important reasons: (i) the use of nonrenewable sources for their synthesis and (ii) the toxicological effects these synthetic compounds exert upon humans and the environment (Dreja et al. 2012; Franzetti et al. 2012). Industries are increasingly investigating biosurfactants as replacements for their synthetic counterparts. A major impediment to this is low yield and high production costs associated with biosurfactant production. This highlights the important need to continually pursue alternative microorganisms that are capable of producing commercially exploitable yields of biosurfactants such as RLs (i.e. $>2000 \mu \mathrm{g} \mathrm{ml}^{-1}$ crude extract) (Marchant and Banat 2012).

Although there has been a significant amount of research on RL synthesis in P. aeruginosa, large-scale production and exploitation are limited due to the pathogenicity of $P$. aeruginosa. A number of different strategies are currently being investigated that either involve identifying an alternative (non-pathogenic) source of RL for commercial use or to genetically modify a non-pathogenic organism to synthesise RLs. Cabrera-Valladares et al. (2006) reported the expression of rhlA, rhlB and rhlC from $P$. aeruginosa PAO1 in Escherichia coli K12; however, RL yield was significantly lower than that in the original donor organism $\left(120 \mu \mathrm{g} \mathrm{ml}^{-1}\right.$ compared with $229 \mathrm{\mu g} \mathrm{ml}^{-1}$ ) (Cabrera-Valladares et al. 2006). Other studies have attempted similar strategies using "nonpathogenic" Pseudomonas species as hosts; although yields were improved compared to recombinant $E$. coli $\left(1500 \mu \mathrm{g} \mathrm{ml}^{-1}\right)$, they were still substantially lower than in wild-type strains of $P$. aeruginosa that when cultured under optimal fermentation conditions can produce yields of up to $40,000 \mu \mathrm{g} \mathrm{ml}^{-1}$ (Wittgens et al. 2011). Reduced yields observed with these approaches may be attributed to the complex level of genetic regulation involved in the synthesis of
RL in $P$. aeruginosa, which includes layered quorum sensing systems (Pearson et al. 1997). Recently, GrossoBecerra et al. (2016) reported recombinant expression of rhlA and rhlB in a "non-pathogenic" P. aeruginosa strain (ATCC9027); this genetic manipulation of the host produced yields comparable to P. aeruginosa PAO1 (approx. yields of $120 \mu \mathrm{g} \mathrm{ml}^{-1}$ for both the "non-pathogenic" $P$. aeruginosa and wild-type PAO1). By omitting the $r h l C$ gene, they were able to engineer a strain that exclusively synthesises mono-rhamnolipid (Grosso-Becerra et al. 2016). Although this approach appears at first to be highly promising from a biotechnological view, many commercial companies are still reluctant to utilise any $P$. aeruginosa strain due to its bio-safety category of 2 .

As an alternative to recombinant synthesis of RLs, a number of studies have identified bacterial species, other than $P$. aeruginosa, that can synthesise RLs. The best-studied example is Burkholderia thailandensis which has been shown to synthesis RLs during the late stationary phase of growth (Dubeau et al. 2009; Funston et al. 2016). Interestingly, the RLs synthesised by $B$. thailandensis significantly differ from those synthesised by $P$. aeruginosa. B. thailandensis synthesises longer chain RLs with Rha-Rha- $\mathrm{C}_{14}-\mathrm{C}_{14}$ being the most abundant congener compared to RLs with acyl chains possessing 10-12 carbons, predominantly seen in $P$. aeruginosa (Rudden et al. 2015; Funston et al. 2016). Synthesis is achieved via a similar mechanism to that found in $P$. aeruginosa; however, the RL synthesis enzymes are expressed from rhlA-C genes that share only $40 \%$ sequence identity with those of $P$. aeruginosa, offering an explanation for the differing congener profile (Dubeau et al. 2009; Funston et al. 2016). Recently, RL production in B. thailandensis has been linked to polyhydroxyalkanoate (PHA) synthesis and storage. B. thailandensis PHA synthase mutants produce significantly higher yields of RL in comparison to the wild-type strain (Funston et al. 2017). It should, however, be noted that the longer chain RL congeners synthesised by $B$. thailandensis possess differing activities to the shorter chain congeners synthesised by $P$. aeruginosa, which could have a marked effect on their potential biotechnological application (Elshikh et al. 2017). In addition to $B$. thailandensis, a number of Pseudomonas species, unrelated to $P$. aeruginosa, have been putatively identified as capable of producing RLs. These include Pseudomonas fluorescens, Pseudomonas chlororaphis, Pseudomonas putida and various others for which species identification has not been determined (Gunther et al. 2005; Vasileva-Tonkova et al. 2006; Martinez-Toledo et al. 2006; Vasileva-Tonkova et al. 2011; Nordin et al. 2013). In many of these studies, RL production was not confirmed by robust qualitative analytical techniques. Additionally, the taxonomic identity of many of these strains has been carried out using unreliable culture-dependent techniques (Irorere et al. 2017). 
Here, we report the isolation of a hydrocarbon degrading marine bacterium belonging to the genus Pseudomonas. Using molecular biology techniques, we show this strain to be taxonomically un-related to $P$. aeruginosa and, using the Galleria mellonella (Wax Worm) larvae model, can be putatively classified as non-pathogenic compared to $P$. aeruginosa. In accordance with the criteria listed by Irorene et al. (2017), the strain was subsequently assessed for evidence of surface-active compound production with RL synthesis being confirmed and characterised by both HPLC-MS and nuclear magnetic resonance (NMR) spectroscopy. Finally, we report that this strain possesses homologues to the RL synthesis genes $r h l A$ and $r h l B$, hence providing evidence for RL synthesis by a new type of non-pathogenic Pseudomonas.

\section{Materials and methods}

\section{Isolation of strain MCTG214(3b1)}

Water samples were collected ( $0.5 \mathrm{~m}$ depth) on 29 July 2009 , from Sarasota Bay (station 4) in Florida $\left(27.4132^{\circ} \mathrm{N},-\right.$ $82.5777^{\circ} \mathrm{W}$ ) during a bloom of Protoperidinium. To isolate polycyclic aromatic hydrocarbon (PAH)-degrading bacteria, enrichment cultures were prepared using acid-washed $(0.1 \mathrm{M} \mathrm{HCl})$, steam-sterilised glass test tubes $(16 \times 125 \mathrm{~mm})$ fitted with screw caps lined with aluminium foil to prevent PAH loss via adsorption. Stock solutions (ca. $3000 \mathrm{mg} \mathrm{l}^{-1}$ ) of phenanthrene, anthracene, fluorene and pyrene dissolved in acetone were prepared. Four sets of six test tubes each were prepared containing one of each of the PAHs and $2.8 \mathrm{ml}$ of ONR7a medium (Dyksterhouse et al. 1995), and then inoculated with $200 \mu \mathrm{l}$ of the water sample from Sarasota Bay. The test tubes were incubated in the dark with gentle shaking $(100 \mathrm{rpm})$ at $21^{\circ} \mathrm{C}$. After 2 and 4 weeks of incubation, $5-\mu 1$ samples were taken from each PAH incubation and streaked onto ONR7a agar plates that were then sprayed with the respective PAH compound used in the enrichments (Kiyohara et al. 1982). The plates were then stored in closed plastic bags in the dark at room temperature. Colonies forming clearing zones were picked, purified and stored frozen at $-80^{\circ} \mathrm{C}$ with the addition of $20 \%(v / v)$ glycerol (Sigma-Aldrich). Following isolation, one strain, designated MCTG214(3b1), was selected for study based on its ability to produce a biosurfactant agent that significantly reduced the surface tension of water. The strain was routinely cultured at $30{ }^{\circ} \mathrm{C}$ in Zobell's 2216 Marine Broth (ZMB). ZMB was composed of $5 \mathrm{~g} \mathrm{l}^{-1}$ BactoPeptone (BD Biosciences) and $1 \mathrm{~g} \mathrm{l}^{-1}$ yeast extract (SigmaAldrich) in artificial sea water (Cold Spring Harbour Laboratory 2012) supplemented with $100 \times$ marine supplements $(1: 100)$ and $1 \%(w / v)$ glucose (Sigma-Aldrich) (Zobell 1941).

\section{Optimisation of MCTG214(3b1) growth parameters}

The growth of MCTG214(3b1) in response to different physical and medium conditions was assessed in shake flask culture. A 50-ml seed culture of MCTG214(3b1) was grown in ZMB supplemented with $1 \%(w / v)$ glucose for $18 \mathrm{~h}$ in a 250 $\mathrm{ml}$ Erlenmeyer flask. In 500-ml Erlenmeyer flasks, the seed culture was used to inoculate $100 \mathrm{ml}$ ZMB incubated for $48 \mathrm{~h}$ with bacterial growth assessed via measurement of optical density (OD) at $600 \mathrm{~nm}$ (Pharmacia Biotech Novaspec II) at 2, 4, 6, 12, 24 and $48 \mathrm{~h}$ growth. Physical and media conditions tested included incubation temperature $\left(25,27,30\right.$ and $\left.37^{\circ} \mathrm{C}\right)$; initial media $\mathrm{pH}$ with the bacteria incubated at $30^{\circ} \mathrm{C}$ in media with a defined $\mathrm{pH}$ of $4.0,5.5,7.0$ and 8.5 ; media salinity with the bacteria incubated at $30{ }^{\circ} \mathrm{C}$ in media with a concentration of $0,5,10,20,30$ and $40 \mathrm{~g} \mathrm{l}^{-1}$ sea salts (Sigma-Aldrich). Additionally, bacterial growth at $30{ }^{\circ} \mathrm{C}$ was assessed with and without the addition of glucose, with and without the addition of marine supplements and in the presence of equal amounts of nitrogen from differing sources (yeast extract/peptone, urea, $\mathrm{NaNO}_{3}$ and $\mathrm{NH}_{4} \mathrm{NO}_{3}$ ). Testing of each physical and/or media condition was carried out using triplicate cultures.

\section{Determination of viable counts and surface tension reduction}

A 50-ml seed culture of MCTG214(3b1) was grown in ZMB supplemented with $1 \%(w / v)$ glucose for $18 \mathrm{~h}$ in a $250-\mathrm{ml}$ Erlenmeyer flask. The seed culture was used to inoculate triplicate 1-1 Erlenmeyer flasks containing $100 \mathrm{ml}$ of ZMB supplemented with $1 \%(v / v)$ rapeseed oil (Sigma-Aldrich) to an initial $\mathrm{OD}_{600 \mathrm{~nm}}$ of 0.01 and incubated at $30^{\circ} \mathrm{C}$. At 4, 8, 18, 24, 48 and $72 \mathrm{~h}, 1 \mathrm{ml}$ from each triplicate flask was removed and dilutions $\left(10^{-3}-10^{-8}\right)$ prepared with ZMB. Samples $(20 \mu \mathrm{l})$ of each dilution were then spotted to ZMB agar plates for bacterial growth assessment via colony forming unit (CFU) determination using the Miles and Misra method. The remaining culture was centrifuged $(10,000 \times g ; 30 \mathrm{~min})$ to pellet the bacterial cells. The resultant cell-free supernatant was transferred to a sterile glass vessel. The surface tension of cell-free supernatant samples was measured via the Du Noüy ring method using a digital tensiometer (Krüss K10ST). For comparison, the surface tension of freshly inoculated culture media $(t=0 \mathrm{~h})$ and of distilled water using the same method.

\section{Extraction and chemical analysis of RL}

To gain a RL production profile, $90 \mathrm{ml}$ of ZMB $+1 \%(v / v)$ rapeseed oil was inoculated with $10 \mathrm{ml}$ of a MCTG214(3b1) seed culture that had been incubated at $30^{\circ} \mathrm{C}$ in $\mathrm{ZMB}$ supplemented with $1 \%(w / v)$ glucose for $18 \mathrm{~h}$. Following incubation for $96 \mathrm{~h}$ at $30{ }^{\circ} \mathrm{C}$ the culture was centrifuged $(13,000 \times g$; 
$20 \mathrm{~min}$ ) to remove most of the cellular biomass. The resultant supernatant was collected, acidified to $\mathrm{pH} 2.0$ with $1 \mathrm{M} \mathrm{HCl}$ (Sigma-Aldrich) and extracted three times with an equal volume of ethyl acetate (Sigma-Aldrich). The organic phase was collected, dried with $0.5 \mathrm{~g}$ anhydrous $\mathrm{MgSO} 4$ (SigmaAldrich) per $100 \mathrm{ml}$ ethyl acetate, then filtered and rotary evaporated to obtain a crude extract containing RLs. All crude extracts were measured gravimetrically. To remove any unwanted impurities from the RL extracts, solid phase extraction (SPE) was carried out using Strata SI-1 Silica ( $55 \mu \mathrm{m}, 70 \AA$ ) Giga tubes (Phenomenex), and the extracts again measured gravimetrically prior to further analysis (Marchant and Banat 2014). The determination of the relative proportion of rhamnolipid present in the extracts was carried out after SPE purification by HPLC-MS. The system used consisted of a LCQ classic MATT ion trap mass spectrometer (ThermoFinnigan) operated in the negative ionisation mode and coupled to a thermo system LC P4000 (ThermoFinnigan) high-performance liquid chromatograph equipped with a $150 \times 4.6$ mm Kinetex $5 \mu \mathrm{M}$ F5 $100 \AA$ LC column. HPLCgrade water and acetonitrile were used as mobile phases 1 and 2 , respectively, while $\mathrm{m} / \mathrm{z}$ range was $110-1200$. The sample injection volume was $10 \mu \mathrm{l}$.

1D and 2D NMR analyses were carried out using a Bruker Avance III High-Definition, four-channel $700 \mathrm{MHz}$ NMR spectrometer equipped with a cryogenically cooled $5 \mathrm{~mm}$ ${ }^{1} \mathrm{H} /{ }^{13} \mathrm{C} /{ }^{15} \mathrm{~N} /{ }^{2} \mathrm{H}$ Z-gradient probe. All analyses were carried out at $298 \mathrm{~K}$ in the solvent system $\mathrm{CDCl}_{3} / \mathrm{MeOD}$ (70:30, $v /$ v). ${ }^{1} \mathrm{H}$ and ${ }^{13} \mathrm{C}$ chemical shifts are reported in parts per million (ppm) relative to residual $\mathrm{CDCl}_{3}$ signal at $7.26 \mathrm{ppm}$ for protons and $77.16 \mathrm{ppm}$ for carbons, respectively. Correlation spectroscopy (COSY), heteronuclear single quantum coherence (HSQC) and heteronuclear multiple-bond correlation spectroscopy (HMBC) were all performed. Assignment of the spectra was carried out according to the literature for glycolipids and rhamnolipids (Bubb 2003; Jensen et al. 2007; Kügler et al. 2014; Chen et al. 2016; Tedesco et al. 2016).

\section{DNA extraction, amplification and sequencing}

Chromosomal DNA was extracted from approx. $1 \times 10^{9}$ cells of MCTG214(3b1) using a DNeasy Blood and Tissue Kit (Qiagen) as per the manufacturer's instructions. DNA was amplified by the polymerase chain reaction (PCR) using primers specific for each target gene (Table S1). PCR amplification was carried out in a Techne TC-5000 thermocycler using recombinant Taq DNA Polymerase (Thermo Fisher Scientific). Reactions were made as per the manufacturer's instructions in a total volume of $50 \mu \mathrm{l}$ using $50 \mathrm{ng}$ template DNA. An initial denaturation step of $94^{\circ} \mathrm{C}$ for 3 min followed by 30 cycles of $94{ }^{\circ} \mathrm{C}$ for $45 \mathrm{~s}$, specific primer annealing temperature (Table S1) for $30 \mathrm{~s}$ and elongation at $72{ }^{\circ} \mathrm{C}$ for $90 \mathrm{~s} / \mathrm{kb}$ of target DNA. PCR products were separated based on molecular weight using a $1 \%(w / v)$ agarose gel made with TBE buffer containing a final concentration of $100 \mathrm{mM}$ Tris, $90 \mathrm{mM}$ boric acid and $1 \mathrm{mM}$ EDTA (Thermo Fisher Scientific). DNA was visualised under UV light using SybrSafe DNA stain (Thermo Fisher Scientific). Amplified DNA was purified using a Wizard Gel and PCR Clean-up System (Promega) and then sequenced using the Sanger sequencing technique by GATC Biotech (Cologne, Germany) with primers specific for each target gene (Table S1).

\section{Cloning of $\mathbf{R L}$ synthesis genes}

Purified RL biosynthesis gene DNA was ligated into pGEM TEasy (Promega) in a 10- $\mu$ l reaction using a 1:3 ratio of vector DNA to insert DNA, T4 DNA Ligase (Promega) and rapid DNA ligase buffer (Promega). DNA ligation reactions were carried at $22{ }^{\circ} \mathrm{C}$ for $60 \mathrm{~min}$ (Sambrook and Russell 2001). Resultant pGEM vector products containing inserted RL biosynthesis genes were transformed into subcloning efficient $E$. coli $\mathrm{DH} 5 \alpha$ competent cells $\left(\mathrm{F}^{-}\right.$\$80lacZ $\Delta \mathrm{M} 15 \Delta$ (lacZYA$\operatorname{argF}) \mathrm{U} 169$ rec $\mathrm{A} 1$ end $\mathrm{A} 1$ hsd $\mathrm{R} 17\left(\mathrm{r}_{\mathrm{k}}{ }^{-}, \mathrm{m}_{\mathrm{k}}{ }^{+}\right)$phoA sup $\mathrm{E} 44$ thi1 gyrA96 relA1 $\lambda^{-}$) (Thermo Fisher Scientific). A 2- $\mu 1$ sample of each DNA ligation was added to $50 \mu \mathrm{l}$ of $E$. coli DH5 $\alpha$. DNA and cells were incubated on ice for 20 min then heat shocked at $42{ }^{\circ} \mathrm{C}$ for $30 \mathrm{~s}$ and returned to ice for a further $2 \mathrm{~min}$. Transformation reactions were then recovered in $950 \mu \mathrm{l}$ of SOC medium and incubated for $1 \mathrm{~h}$ at $37^{\circ} \mathrm{C}$. Following recovery, $100 \mu \mathrm{l}$ of each transformation was plated onto nutrient broth (NB) agar (Oxoid) supplemented with $100 \mu \mathrm{g} \mathrm{ml}^{-1}$ ampicillin, $80 \mu \mathrm{g} \mathrm{ml}^{-1} \mathrm{X}$-Gal and $50 \mu \mathrm{M}$ IPTG (Sigma-Aldrich) and incubated at $37^{\circ} \mathrm{C}$ for $18 \mathrm{~h}$ (Sambrook and Russell 2001). Transformant colonies were selected for further analysis based on blue/white selection and incubated for $18 \mathrm{~h}$ at $37^{\circ} \mathrm{C}$ in $10 \mathrm{ml} \mathrm{NB}$ supplemented with $100 \mu \mathrm{g} \mathrm{ml}^{-1}$ ampicillin. Plasmid DNA was recovered from each selected transformant strain using a QIAprep Spin Miniprep Kit (Qiagen) following the manufacturer's instructions. The presence of insert DNA in the recovered plasmids was confirmed by a restriction enzyme digest using EcoRI (Sigma-Aldrich) carried out as per the manufacturer's instructions, followed by separation on a $1 \%(w / v)$ agarose gel as previously described. Plasmid DNA with the correct size insert fragments was sequenced using the Sanger sequencing technique by GATC Biotech (Cologne, Germany) with the M13 forward and reverse primers.

\section{Galleria mellonella infection model}

Assessment of the virulence of MCTG214(3b1) using the $G$. mellonella infection model was carried out using a protocol based on Hill et al. (2014). As a comparative positive control for these experiments, P. aeruginosa PAO1 (ATCC 15692) was routinely cultured at $37^{\circ} \mathrm{C}$ in $\mathrm{NB}$ (Oxoid). Ten millilitres 
of stationary phase culture was centrifuged $(10,000 \times g$; $20 \mathrm{~min}$ ) to pellet the cells, which were then washed in sterile phosphate-buffered saline (PBS). Washed cells were resuspended to $\mathrm{OD}_{600 \mathrm{~nm}} 0.4$ in PBS. The CFU count at $\mathrm{OD}_{600 \mathrm{~nm}} 0.4$ was established using the Miles and Misra method and the samples diluted in sterile PBS to a concentration of $1 \times 10^{3} \mathrm{CFU} \mathrm{ml}^{-1}$. G. mellonella larvae were purchased from Pets at Home (Belfast) and larvae of approx. $20 \mathrm{~mm}$ in length and $200 \mathrm{mg}$ in weight were selected. Twenty microlitres of either bacterial sample or PBS (negative control) was injected using a $0.30 \mathrm{~mm}(30 \mathrm{G}) \times 8 \mathrm{~mm}$ hypodermic needle $(B D)$ into the last pro-leg of individual larvae $(n=10$ per experimental group) and the larvae then incubated at $37^{\circ} \mathrm{C}$ for $48 \mathrm{~h}$. The larvae were observed at set time points during the course of the 48-h period and recorded as either live or dead for each individual larva at each time point. The experiment was carried out on three independent occasions and the data pooled to give and $n$ of 30 per experimental group (Hill et al. 2014).

\section{Sequence data}

All sequencing data was submitted prior to publication to the GeneBank Centre (NCBI, USA), and the accession numbers were MG786779 (16S rDNA), MG805347 (gryB), MG805348 (rhlA) and MG805349 (rhlB).

\section{Results}

\section{Isolation of and identification of strain MCTG214(3b1)}

Strain MCTG214(3b1) was isolated from an enrichment of PAHs of a phytoplankton bloom field sample collected in the summer of 2009 at Sarasota Bay (USA). Selection of this strain for further study was based on preliminary screening for surface tension reduction, emulsification, gelling and foaming ability (data not shown). Taxonomic identification of MCTG214(3b1) was ascertained by sequencing and BLASTn analysis of two phylogenetic markers the $16 \mathrm{~S}$ rRNA gene (GeneBank MG786779) and the DNA gyrase subunit B gene $($ gryB) (GeneBank MG805347) showed MCTG214(3b1) to belong to the genus Pseudomonas. Comparison via sequence alignment to each marker gene from the type strains of 21 separate species belonging to the genus Pseudomonas showed MCTG214(3b1) to be closely related to both Pseudomonas pseudoalcaligenes and Pseudomonas oleovorans based on $16 \mathrm{~S}$ rRNA and Pseudomonas mendocina based on $\operatorname{gyr} B$ (Fig. S1). The new isolate, identified as Pseudomonas sp. MCTG214(3b1), was deposited in the Deutsche Sammlung von Mikroorganismen und Zellkulturen (DSMZ) culture collection (DSM 105446).

\section{Growth and surface tension reducing ability of Pseudomonas sp. MCTG214(3b1)}

The growth of Pseudomonas sp. MCTG214(3b1) in ZMB was assessed at a range of temperatures, initial medium $\mathrm{pH}$, medium salinity, defined carbon/nitrogen source and in the presence/absence of Zobell's marine supplements (Fig. S2). Incubation temperature and presence/absence of Zobell's marine supplements showed no significant effect on bacterial growth. Initial medium $\mathrm{pH}$ of 5.5 and 8.5 showed no significant effect on bacterial growth when compared to growth in media with an initial $\mathrm{pH}$ of 7.0 ; however, growth was significantly reduced in media with an initial $\mathrm{pH}$ of 4 . Bacterial growth in the absence $\left(0 \mathrm{~g} \mathrm{l}^{-1}\right)$ of sea salts was significantly reduced when compared to growth in $5-40 \mathrm{~g} \mathrm{l}^{-1}$ sea salts; however, there was no significant effect on bacterial growth in medium containing between 5 and $40 \mathrm{~g} \mathrm{l}^{-1}$ sea salts. Bacterial growth in medium containing urea, $\mathrm{NaNO}_{3}$ or $\mathrm{NH}_{4} \mathrm{NO}_{3}$ as a defined nitrogen source was significantly reduced compared to growth in a medium where the defined nitrogen source was a mixture of peptone and yeast extract. Finally, bacterial growth was significantly increased in the presence of $1 \%(w / v)$ glucose compared to an absence of a defined carbon source.

Bacterial growth and the ability of Pseudomonas sp. MCTG214(3b1) to reduce surface tension at an air-liquid interface was assessed throughout a 72 -h growth period in ZMB supplemented with $1 \%(v / v)$ rapeseed oil. When compared to samples obtained from cultures at $t=0 \mathrm{~h}$, the surface tension was significantly reduced in samples measured from the late exponential growth phase through to stationary growth phase (Fig. 1). The effect on surface tension was most profound during the early stationary phase of growth (approx. $t=$ $24 \mathrm{~h}$ ) where mean surface tension was measured at $30.13 \mathrm{mN} \mathrm{M}^{-1}\left( \pm 0.20 \mathrm{mN} \mathrm{M}^{-1}\right)$. This reduction in surface tension was observed to be relatively constant throughout the stationary growth phase $(\mathrm{t}=24 \mathrm{~h}-t=72 \mathrm{~h})$.

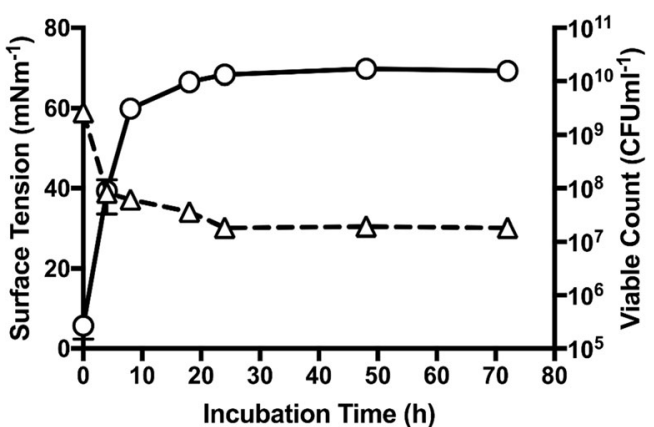

Fig. 1 Cell-free supernatant samples obtained from Pseudomonas sp. MCTG214(3b1) during growth in ZMB supplemented with rapeseed oil show a reduction in surface tension during the late-exponential and stationary growth phases. Symbols: surface tension $(\Delta)$ and biomass $(\circ)$. Error bars represent standard deviation from the mean $(n=3)$ 


\section{Chemical analysis of biosurfactant synthesis}

The ability of Pseudomonas sp. MCTG214(3b1) to reduce the surface tension of the culture supernatant during the stationary growth phase suggested the synthesis of a low molecular weight biosurfactant. To assess this crude liquid phase, solvent extract obtained from cell-free stationary phase culture supernatant was obtained and gravimetrically assessed. Crude extract obtained from cultures of Pseudomonas sp. MCTG214(3b1) showed a biosurfactant yield of $2.6 \mathrm{~g} \mathrm{l}^{-1}$. Following further purification using SPE columns, purified biosurfactant yield was shown to be $0.457 \mathrm{~g} \mathrm{l}^{-1}$. To elucidate the chemical structure of the biosurfactant(s) synthesised by Pseudomonas sp. MCTG214(3b1), the purified extract was analysed by both HPLC-MS and NMR spectroscopy. The HPLC-MS profile obtained from SPE purified extracted supernatant samples of Pseudomonas sp. MCTG214(3b1) showed the presence of predominant peaks corresponding to the molecular weight of five rhamnolipid congeners (Fig. 2). HPLC-MS produced a good separation of these $\mathrm{RL}$ congeners and the relative percentage of each congener was ascertained (Table 1). Four out of five of these RL congeners were di-rhamnolipids and accounted for a total relative abundance of $87.74 \%$. The two predominantly abundant congeners synthesised by Pseudomonas sp.
MCTG214(3b1) were Rha-Rha- $\mathrm{C}_{10}-\mathrm{C}_{10}(42.75 \%)$ and Rha-Rha- $\mathrm{C}_{10}(23.80 \%)$. From this analysis, no rhamnolipid congeners possessing fatty acid chains longer than 12 carbon are synthesised by Pseudomonas sp. MCTG214(3b1).

NMR data from the ${ }^{1} \mathrm{H}^{13}{ }^{13} \mathrm{C} 2 \mathrm{D}$ HSQC spectrum exhibited six distinct spin systems (4.60-5.50 to $92.4-102.4 \mathrm{ppm})$ indicating the presence of sugar ring moieties in the SPE-purified extracted supernatant samples of MCTG214(3b1). The presence of the carbonyl ester protons at $5.27 \mathrm{ppm}(\mathrm{p}, 6.44 \mathrm{~Hz})$ along with the signals arising from the protons located in the sugar ring provides strong experimental evidence for the presence of glycolipid (data not shown). These data were also supported by the scalar connectivities identified between these protons in ${ }^{1} \mathrm{H}-{ }^{1} \mathrm{H} 2 \mathrm{D}$ COSY and ${ }^{1} \mathrm{H}_{-}{ }^{13} \mathrm{C} 2 \mathrm{D} \mathrm{HMBC}$ spectra. In the ${ }^{1} \mathrm{H}-{ }^{1} \mathrm{H}$ 2D COSY spectrum, through-bond correlations between anomeric protons and the adjacent protons of the sugar unit were observed. A strong correlation was also observed between a methyl group at $1.13 \mathrm{ppm}$ and a proton at $3.76 \mathrm{ppm}$ placing the methyl group at position $\mathrm{C} 5$ in a pentose ring indicating the existence of a rhamnose ring (Fig. 3). The proposed structure was fully supported by additional, longrange through-bond, correlations from ${ }^{1} \mathrm{H}-{ }^{13} \mathrm{C} 2 \mathrm{D}$ HMBC spectrum indicating that the sample obtained from the extraction of MCTG214 contained a rhamnolipid profile (Fig. 3).

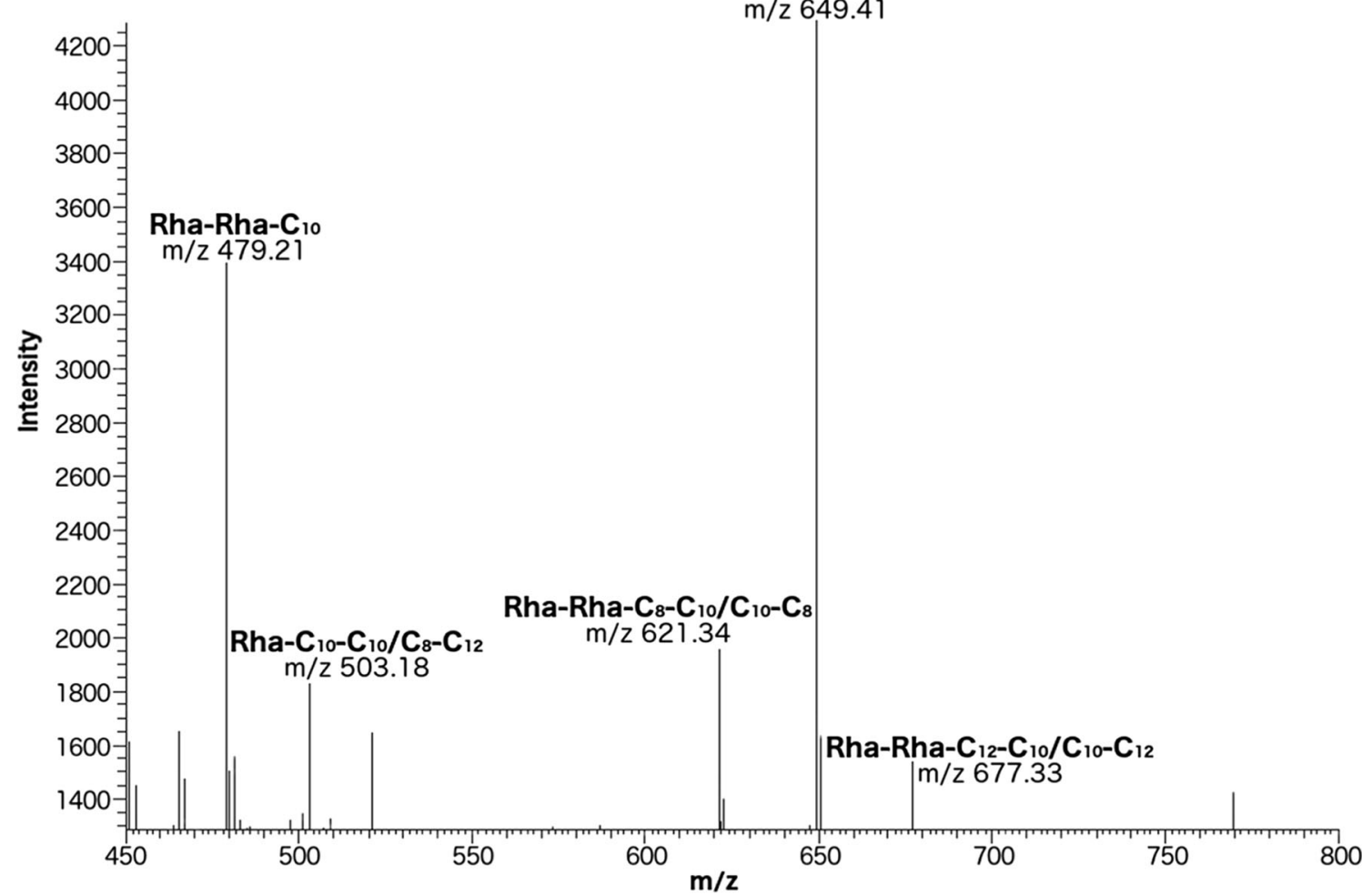

Fig. 2 HPLC-MS profile of a SPE purified extract obtained from Pseudomonas sp. MCTG214(3b1) cell-free supernatant samples. The predominant peaks were identified as Rha-Rha- $\mathrm{C}_{10}$ and Rha-Rha- $\mathrm{C}_{10}-\mathrm{C}_{10}$ 
Table 1 Rhamnolipid congeners synthesised by Pseudomonas sp. MCTG214(3b1) and the percentage relative abundance of each congener

\begin{tabular}{lllllc}
\hline RT min & $\mathrm{m} / \mathrm{z}$ & Compound & $\mathrm{M}_{\mathrm{w}}$ & Mol. Form & Relative \% \\
\hline 13.31 & 479.21 & Rha-Rha- $\mathrm{C}_{10}$ & 480.55 & $\mathrm{C}_{22} \mathrm{H}_{40} \mathrm{O}_{11}$ & 23.80 \\
13.36 & 649.41 & Rha-Rha- $\mathrm{C}_{10}-\mathrm{C}_{10}$ & 650.79 & $\mathrm{C}_{32} \mathrm{H}_{58} \mathrm{O}_{13}$ & 42.74 \\
14.29 & 503.18 & Rha- $\mathrm{C}_{10}-\mathrm{C}_{10} / \mathrm{C}_{8}-\mathrm{C}_{12}$ & 504.65 & $\mathrm{C}_{26} \mathrm{H}_{48} \mathrm{O}_{9}$ & 12.26 \\
14.54 & 677.33 & Rha-Rha- $\mathrm{C}_{10}-\mathrm{C}_{12} / \mathrm{C}_{12}-\mathrm{C}_{10}$ & 678.84 & $\mathrm{C}_{34} \mathrm{H}_{62} \mathrm{O}_{13}$ & 9.78 \\
32.31 & 621.34 & Rha-Rha- $\mathrm{C}_{8}-\mathrm{C}_{10} / \mathrm{C}_{10}-\mathrm{C}_{8}$ & 622.74 & $\mathrm{C}_{30} \mathrm{H}_{54} \mathrm{O}_{13}$ & 11.42 \\
\hline
\end{tabular}

These data in combination with HPLC-MS data clearly support the synthesis of rhamnolipid by Pseudomonas sp. MCTG214(3b1).

\section{Screening for RL synthesis genes}

In $P$. aeruginosa, rhamnolipids are synthesised by enzymes expressed from the genes $r h l A, r h l B$ and $r h l C$. Using primers designed to bind within the coding region of these three $P$. aeruginosa genes, the presence of $r h l A, r h l B$ and $r h l C$ in genomic DNA extracted from Pseudomonas sp. MCTG214(3b1) was screened by PCR. PCR screening using rhlA and rhlB primers amplified products of the same molecular weight (approx. 850 and $900 \mathrm{bp}$, respectively), when chromosomal DNA extracted from both Pseudomonas sp. MCTG214(3b1) and $P$. aeruginosa PAO1 DNA was provided has a template (Fig. 4). PCR screening using primers specific for rhlC amplified no product in Pseudomonas sp. MCTG214(3b1) matching the molecular weight of that amplified in $P$. aeruginosa PAO1. Additional screening using primers designed from the coding region of the $B$. thailandensis rhlC homologue also failed to amplify any product in Pseudomonas sp. MCTG214(3b1). The putative rhlA and $r h l B$ DNA amplified from Pseudomonas sp. MCTG214(3b1) chromosomal DNA was subsequently cloned into pGEM-T Easy and sequenced from the purified plasmid ( $r h l A-G e n e B a n k$ MG805348 and rhlB-GeneBank MG805349). BLASTn sequence analysis showed that the DNA amplified from Pseudomonas sp. MCTG214(3b1) matched $r h l A$ and $r h l B$ from multiple strains of $P$. aeruginosa with a sequence homology averaging 99\%. Further analysis showed that the translated $r h l A$ and $r h l B$ sequences of MCTG214(3b1) possessed an average 96\% amino acid sequence identity to RhlA sequences obtained from multiple $P$. aeruginosa strains and $98 \%$ amino acid sequence identity to RhlB sequences obtained from the same multiple $P$. aeruginosa strains.

\section{Assessment of virulence using the Galleria mellonella infection model}

The potential virulence of Pseudomonas sp. MCTG214(3b1) was assessed and compared to that of the RL producing opportunistic pathogen $P$. aeruginosa. P. aeruginosa
PAO1 was shown to kill $100 \%$ of the infected larvae $24 \mathrm{~h}$ post-inoculation with as little as $20 \mathrm{CFU}$ (Fig. 5). When inoculated with an equal CFU count of Pseudomonas sp. MCTG214(3b1) or with sterile PBS, the larvae showed $100 \%$ survival $48 \mathrm{~h}$ post-inoculation, (Fig. 5).

\section{Discussion}

Biosurfactants such as RLs are increasingly viewed by industry as attractive replacements for artificially synthesised surfactant compounds with applications in the home care, food, pharmaceutical and petrochemical sectors (Banat et al. 2010). Whilst the best-characterised bacterium to synthesise RLs is $P$. aeruginosa, large-scale culture of this species is problematic due to this organism's status as a biological safety level 2 pathogen (Soberón-Chávez et al. 2005; Abdel-Mawgoud et al. 2010). Bacteria are thought to synthesise surface-active compounds such as RLs, in part to help solubilise poorly soluble substrates such as hydrocarbons and hence enhance their bioavailability and subsequent metabolism (AbdelMawgoud et al. 2010). Several studies have reported the isolation of hydrocarbon-degrading bacteria from laboratory cultures of phytoplankton across the three main lineages (diatoms, dinoflagellates and coccolithophores) (Green et al. 2004; Green et al. 2006; Gutierrez et al. 2012a; Gutierrez et al. 2012b; Gutierrez et al. 2013; Gutierrez et al. 2014; Mishamandani et al. 2016). Some were identified through sequencing surveys in field samples of phytoplankton (Gutierrez et al. 2011; Thompson et al. 2017). The occurrence of hydrocarbon-degrading bacteria with phytoplankton may be more frequent and important in the global ocean environment than previously perceived, including as a source for discovering novel types of biosurfactants such as RLs. Whilst there is a plethora of previous studies reporting $\mathrm{RL}$ production in bacteria other than $P$. aeruginosa, many of them either fail to prove $\mathrm{RL}$ synthesis utilising robust chemical analysis techniques or they do not provide accurate identification of the strain investigated. Irorere et al. (2017) recently published a number of criteria for how to confirm bacterial biosurfactant production, such as, for example using HPLC-MS for the analysis of supernatant extracts, detection of biosurfactant synthesis genes using molecular 


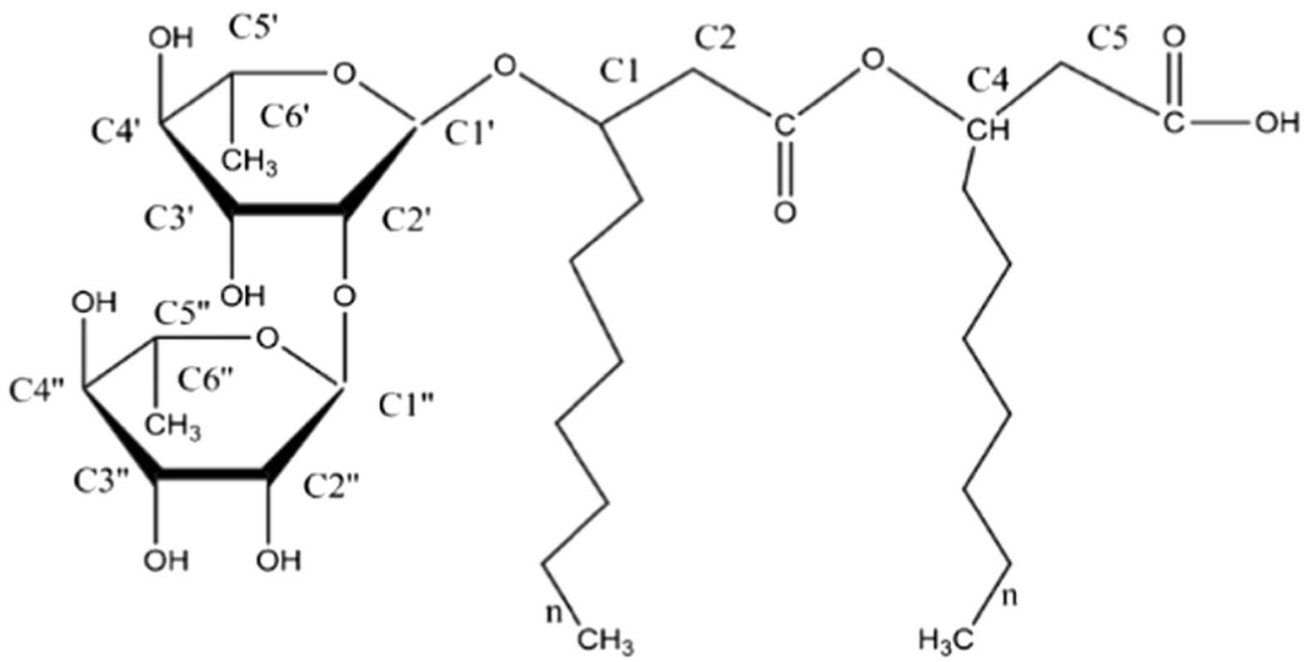

\begin{tabular}{|c|c|c|c|c|}
\hline Anomeric C & $\delta_{\mathrm{H}}$, multi $\left(\mathrm{J}_{\mathrm{HH}} \mathrm{Hz}\right)$ & ${ }^{1} \mathrm{H}-{ }^{1} \mathrm{H}$ CosY & ${ }^{13} \mathrm{C}$ (ppm) & ${ }^{1} \mathrm{H}-{ }^{13} \mathrm{C}$ 2D HMBC \\
\hline C1' & 4.72 & 3.78 & 102 & $68.3,71.2,79.1$ \\
\hline $\mathrm{C} 2$ & 3.78 & $4.72,3.55$ & 72.9 & $26.9,72.7$ \\
\hline C3' & 3.55 & $3.78,3.03$ & 71.1 & $63.9,73.4,102.8$ \\
\hline C4' & 3.03 & $3.55,3.76$ & 72.6 & $17.4,26.6,68.3,70.2$ \\
\hline C5' & 3.76 & $3.03,1.67$ & 68.6 & \\
\hline C6 & 1.13 & 3.76 & 17.7 & $13.9,32.3,68.9,73.4$ \\
\hline $\mathrm{C} 1$ & $5.27, \mathrm{p}(6.44)$ & $2.54,1.67$ & 73.4 & $25.1,(34.6), 41.8,172.5,177.0$ \\
\hline $\mathrm{C} 2$ & 2.54 & & 38.3 & 128,130 \\
\hline C3 & & & $172.3,177.4$ & \\
\hline $\mathrm{C} 4$ & 4.05, - (overlap) & $2.54,1.59$ & 71.1 & $25.2,168.6$ \\
\hline iC5 ${ }^{\star}$ & 1.67 & 1.23 & 25.0 & $12.6,23.1,39.8,46.8$ \\
\hline $\mathrm{iiC5} 5^{\star}$ & 1.59 & 1.05 & 24.7 & $21.2,22.8$ \\
\hline $\mathrm{BCH}_{2}-\mathrm{COO}-\mathrm{R}^{\star *}$ & 2.26 & $4.26,5.55$ & 35.7 & $32.9,73.0,172.3,176.5,179.0$ \\
\hline $\mathrm{CH}_{2}-\mathrm{C}=\mathrm{C}-\mathrm{CH}_{2}$ & $2.10, \mathrm{~m}$ & 1.73 & 35.1 & $25.3,28.8,37.0,68.9,177.7$ \\
\hline $\mathrm{aCH}_{2}-\mathrm{COO}-\mathrm{R}^{\star \star}$ & $2.46, \mathrm{~m}(7.70)$ & 2.36 & 35.1 & $26.9,112.6,172.3$ \\
\hline$-\mathrm{CH}_{2-}^{-}$ & $1.04-1.19$ & 1.44 & $22-30$ & 20.9 \\
\hline
\end{tabular}

Fig. 3 NMR resonance assignment of SPE purified supernatant extracts obtained from Pseudomonas sp. MCTG214(3b1). The table reports the chemical shifts of hydrogen and carbon nuclei, multiplicity of the peak and coupling constants. The diagram above the table shows the generic

biology tools and phylogenetic identification of the strains of interest (Irorere et al. 2017). Here, we employ these criteria to confirm the production of RLs by the new isolate Pseudomonas sp. MCTG214(3b1). molecular structure of a RL congener with carbon atoms of the rhamnose unit numbered from 1'-6' and acyl chain from 1 to 5 , this numbering relates to the numbering of anomeric carbon within the table

The sequencing of the two phylogenetic markers, $16 \mathrm{~S}$ rDNA and DNA gyrase B $(g y r B)$ produced conflicting results since using the former identified the strain as Pseudomonas pseudoalcaligenes, whereas with $\operatorname{gyr} B$, the strain was 
Fig. 4 DNA fragments resulting from PCR amplification of rhamnolipid synthesis genes $r h l A$ (a) and $r h l B$ (b). PCR products were separated by molecular weight on a $1.5 \%(w / v)$ agarose gel, imaged under UV light using SybrSafe DNA strains (Thermo Fisher Scientific). Samples from left to right on each gel; $1 \mathrm{~kb}$ Plus DNA marker (Thermo Fisher Scientific), amplification product from $P$. aeruginosa PAO1, amplification product from Pseudomonas sp. MCTG214(3b1)
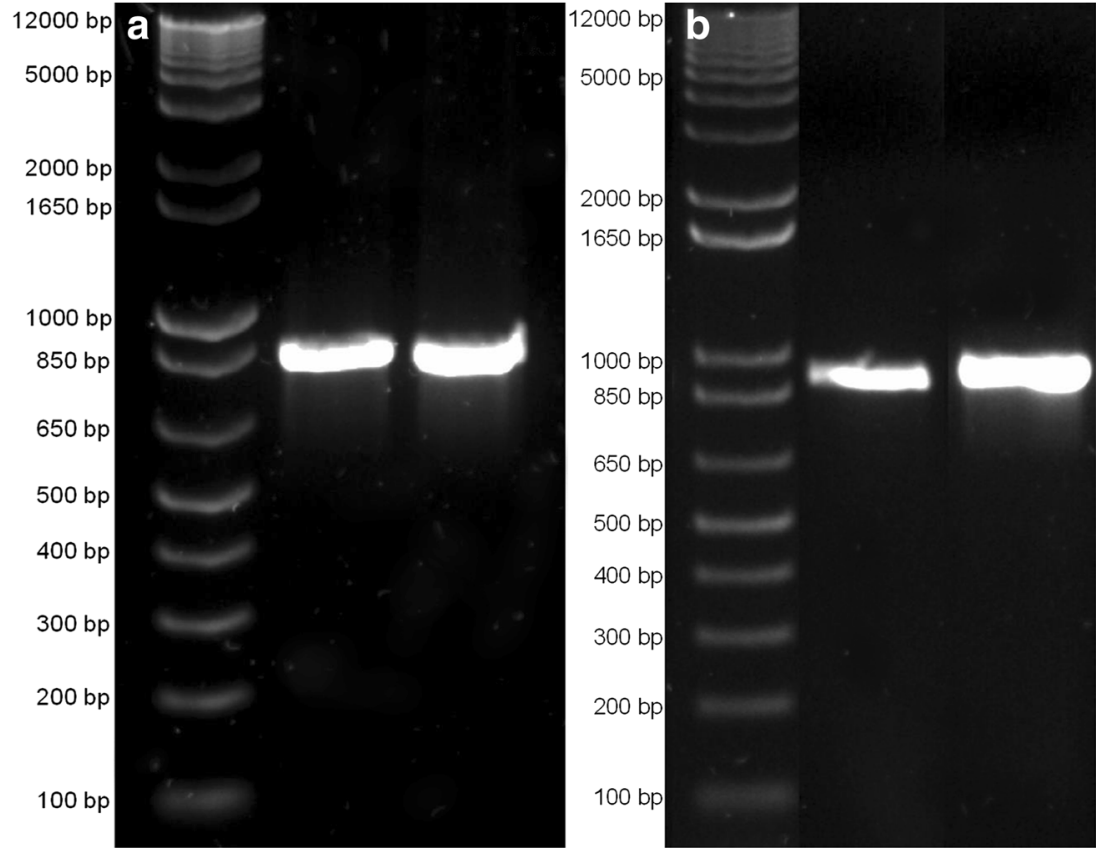

identified as Pseudomonas mendocina. Based on DNA-DNA relatedness and molecular profiling, Pseudomonas pseudoalcaligenes has now been re-classified as Pseudomonas oleovorans (Saha et al. 2010). Both P. oleovorans and P. mendocina have been previously isolated from varying environmental niches, including the marine environment (Xu et al. 2006; Shi et al. 2009; Mangwani et al. 2014). A study investigating taxonomic relatedness of Pseudomonas species using $112 \mathrm{draft}$ Pseudomonas genomes and 141 well-characterised Pseudomonas strains showed 16 subgroups to be present within the genus (Gomila et al. 2015). $P$. oleovorans and $P$. mendocina belong to the same clade within the genus, which is separate from the clade containing P. aeruginosa (Gomila et al. 2015). There is limited evidence

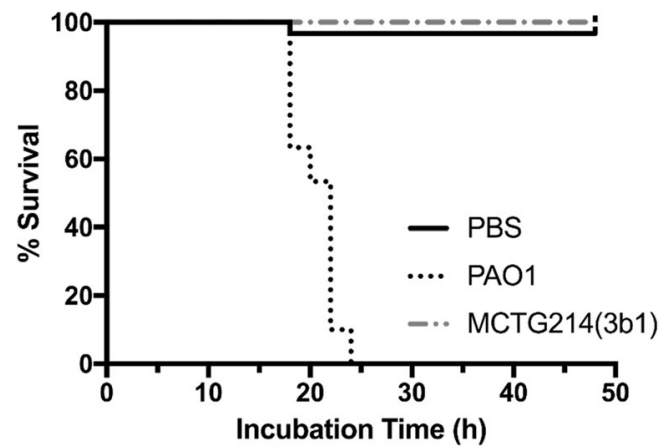

Fig. 5 Kaplan-Meier plot showing percentage survival of Galleria mellonella larvae after inoculation with either Pseudomonas sp. MCTG214(3b1) or P. aeruginosa PAO1. No significant mortality was observed after infection with Pseudomonas sp. MCTG214(3b1) within a 48-h incubation as opposed to infection with $P$. aeruginosa PAO1 where $100 \%$ mortality was observed within 24 -h incubation. No significant mortality was observed in larvae inoculated with the carrier control buffer (PBS). $n=30$ (pooled from $3 \times$ duplicate experiments) that these two species can cause infection; however, these cases appear to be confined to persons with compromised immune systems (Johansen et al. 2001; Faccone et al. 2014; Gautam et al. 2015). To ascertain that Pseudomonas sp. MCTG214(3b1) is less pathogenic than $P$. aeruginosa, this study utilised the G. mellonella model. G. mellonella larvae possess a basic innate immune system analogous to a neutrophil response in humans, and it has been used in multiple studies investigating virulence in a number of bacterial species (Mukherjee et al. 2011; Tsai et al. 2016). Larvae inoculated with Pseudomonas sp. MCTG214(3b1) showed no pathogenic effect on the G. mellonella after 48 -h incubation at $37^{\circ} \mathrm{C}$ compared to those inoculated with the same CFU of $P$. aeruginosa PAO1 where $100 \%$ mortality was observed within 24-h incubation. In addition to a lack of any observable pathogenicity to $G$. mellonella, strains of both $P$. oleovorans and $P$. mendocina deposited in various culture collections, including the ATCC, are reported to be biological safety category 1 .

Analysis of cell-free supernatant samples obtained from stationary phase cultures of Pseudomonas sp. MCTG214(3b1) showed significant reduction in surface tension. This profile of surface tension reduction is similar to that previously observed and attributed to RL production in $P$. aeruginosa (Ismail et al. 2015). To conclusively link this observation of surface tension reduction in Pseudomonas sp. MCTG214(3b1) cultures with the production of biosurfactant compounds, the qualitative analytical techniques, HPLC-MS and NMR spectroscopy, were employed. HPLC-MS spectra obtained from the SPEpurified supernatant extracts showed peaks indicative of five separate RL congeners, a significant majority which were shown to possess a molecular structure that included 
two rhamnose moieties, i.e. di-rhamnolipids. The synthesis of RL congeners by Pseudomonas sp. MCTG214(3b1) identified by HPLC-MS was supported by data from NMR spectroscopy analysis which elucidated ${ }^{1} \mathrm{H}$ and ${ }^{13} \mathrm{C}$ resonances indicative of glycolipid molecules containing rhamnose moieties. The di-rhamnolipid congeners synthesised by this strain totalled a relative abundance of $87.74 \%$. Although a strong prevalence towards di-rhamnolipid synthesis in bacteria such as $P$. aeruginosa and $B$. thailandensis is commonly reported, this level of dirhamnolipid abundance appears to be significantly higher than in other wild-type strains (Rudden et al. 2015; Funston et al. 2016). The virtually exclusive synthesis of di-rhamnolipids by Pseudomonas sp. MCTG214(3b1) is advantageous for biotechnological application due to no genetic manipulation of the strain being required to select for these congeners. The $\beta$-hydroxy fatty acid moieties incorporated into RL congeners synthesised by Pseudomonas sp. MCTG214(3b1) varied between 8 and 12 carbons in length, similar to those shown to be incorporated into RLs synthesised by $P$. aeruginosa (Rudden et al. 2015). This differs from those incorporated by $B$. thailandensis which shows a preference towards fatty acids of longer (12-14 carbons) chain length (Funston et al. 2016). Indeed, the RL congener shown to be most prevalently synthesised by Pseudomonas sp. MCTG214(3b1), Rha-Rha- $\mathrm{C}_{10}-\mathrm{C}_{10}$, is identical to that which is most prevalently synthesised by P. aeruginosa (Rudden et al. 2015). Although the profile of di-rhamnolipids synthesised by Pseudomonas sp. MCTG214(3b1) is highly similar to $P$. aeruginosa, there are differences such as the predominant synthesis of congener Rha-Rha- $\mathrm{C}_{10}$, which appears to be unique to this strain.

Using RL-specific gene primers for PCR, this study identified Pseudomonas sp. MCTG214(3b1) to possess homologues to the rhamnolipid synthesis genes rhlA and $r h l B$. The combination of both enzymes encoded by these genes is responsible for the rhamnosyltransferase that synthesises mono-rhamnolipids. RhlA forms the HAA precursor molecules and RhlB adds rhamnose sugar moieties to form the completed RL (Ochsner et al. 1994; Rahim et al. 2001; Deziel et al. 2003). The presence of these two genes indicates Pseudomonas sp. MCTG214(3b1) is genetically capable of RL synthesis. The DNA sequence of $r h l A$ and $r h l B$ amplified from Pseudomonas sp. MCTG214(3b1) possessed over 98\% homology to rhlA and rhlB in P. aeruginosa. The high level of sequence homology to $P$. aeruginosa contrasts to the observation of Funston et al. (2016) who showed $r h l A / B$ homologues present in $B$. thailandensis that were below $50 \%$ homology to those present in $P$. aeruginosa (Funston et al. 2016). The high level of sequence homology to $P$. aeruginosa may indicate evolution of the rhamnosyltransferase gene operon within the Pseudomonas genus from a joint ancestor or horizontal gene transfer within the genus. The high level of rhlA sequence homology between $P$. aeruginosa and Pseudomonas sp. MCTG214(3b1) may cause the expression of enzymes of similar high amino acid sequence identity and therefore corresponding substrate prevalence. This could account for the comparable synthesis of short chain RLs to those synthesised by $P$. aeruginosa and contrast to those synthesised by $B$. thailandensis where sequence identity is low.

The mechanism for di-rhamnolipid synthesis in both $P$. aeruginos $a$ and $B$. thailandensis is well established with the process involving the addition of a second rhamnose sugar to the mono-rhamnolipid already generated by the actions of RhlA/B (Ochsner et al. 1994; Deziel et al. 2003; Zhu and Rock 2008; Dubeau et al. 2009). The addition of the second rhamnose is catalysed by a second rhamnosyltransferase enzyme RhlC (Rahim et al. 2001). In P. aeruginosa, this second rhamnosyltransferase is expressed from the gene $r h l C$ located approximately $1 \mathrm{Mb}$ downstream on the genome from the rhlA/B genes (Stover et al. 2000). The $B$. thailandensis rhlC homologue is found within the same operon as the $r h l A / B$ homologues (Dubeau et al. 2009). As with the $r h l A / B$ genes, $r h l C$ found in $P$. aeruginosa shares a low sequence homology to its functional homologue in B. thailandensis (Dubeau et al. 2009; Funston et al. 2016). HPLC-MS analysis of Pseudomonas sp. MCTG214(3b1) products clearly identified di-rhamnolipid congeners, and it was expected that this strain would also possess an $r h l C$ homologue with high sequence homology to P. aeruginosa. When chromosomal DNA from Pseudomonas sp. MCTG214(3b1) was probed using primers designed for identifying this gene in $P$. aeruginosa, no amplified product was identified. Further screening using primers designed for $B$. thailandensis also yielded negative results.

The clear production of di-rhamnolipid by Pseudomonas sp. MCTG214(3b1) and lack of $r h l C$ presents an anomaly. If the $r h l A / B$ genes in Pseudomonas sp. MCTG214(3b1) were acquired via horizontal gene transfer from $P$. aeruginosa, it is feasible that $r h l C$ would not have been acquired in the same manner due to the sizeable gap between the $r h l A / B$ genes and rhlC in P. aeruginosa (Stover et al. 2000; Deziel et al. 2003). We therefore postulate that di-rhamnolipid synthesis observed in Pseudomonas sp. MCTG214(3b1) is catalysed by a novel second rhamnosyltransferase. We also posit that this would account for the subtle differences in RL congener profile in Pseudomonas sp. MCTG214(3b1) compared to that of $P$. aeruginosa, and importantly the observation of nearly total conversion of mono-rhamnolipid to di-rhamnolipid. Based on the RL profile of Pseudomonas sp. MCTG214(3b1), this novel RhlC is likely to have a higher substrate affinity for mono-rhamnolipid than RhlC from either P. aeruginosa or $B$. thailandensis where the reported relative abundances of di-rhamnolipid are 62.85 and $79.33 \%$, respectively (Rudden et al. 2015; Funston et al. 2016). Differences in gene expression profile to account for the near total conversion of mono- 
rhamnolipid by Pseudomonas sp. MCTG214(3b1) can be discounted since the surface tension reduction profiles of both Pseudomonas sp. MCTG214(3b1) and P. aeruginosa are highly similar. The identification and characterisation of this putative $r h l C$ gene responsible for the near exclusive dirhamnolipid synthesis and the analysis of the expression of $r h l A / B$ homologues identified in this study will be the focus of future work. Future work will also include an investigation of regulatory pathways that govern RL synthesis in Pseudomonas sp. MCTG214(3b1) which, as in both $P$. aeruginosa and $B$. thailandensis, may be modulated through AHL-mediated quorum sensing systems (Pearson et al. 1997; Funston et al. 2016).

This study has extended the number of species producing RL within the Pseudomonas genus to include a previously un-investigated marine strain MCTG214(3b1). Confirmed identification of RL production in a bacterial strain isolated from phytoplankton bloom highlights marine phytoplankton as an untapped resource in the ocean for the discovery of novel types of biosurfactants. Additionally, the discovery that this strain in its wild-type form appears to synthesise a significantly high proportion of di-rhamnolipid may have important biotechnological application that can be further investigated.

Acknowledgments We also thank, K.D. Marousis (UPAT) for recording the NMR data. VUI would also like to acknowledge the support of an Ulster University Vice Chancellors Research Scholarship.

Funding This work was supported by a grant from The European Union's Horizon 2020 research and innovation programme under Grant agreement No. 635340 (MARISURF).

\section{Compliance with ethical standards}

Conflict of interest The authors declare that they have no conflict of interest.

Ethical approval This article does not contain any studies with human participants or where ethical approval for use of animals is required.

Open Access This article is distributed under the terms of the Creative Commons Attribution 4.0 International License (http:// creativecommons.org/licenses/by/4.0/), which permits unrestricted use, distribution, and reproduction in any medium, provided you give appropriate credit to the original author(s) and the source, provide a link to the Creative Commons license, and indicate if changes were made.

\section{References}

Abdel-Mawgoud AM, Lépine F, Déziel E (2010) Rhamnolipids: diversity of structures, microbial origins and roles. Appl Microbiol Biotechnol 86:1323-1336. https://doi.org/10.1007/s00253-0102498-2
Banat IM, Franzetti A, Gandolfi I, Bestetti G, Martinotti MG, Fracchia L, Smyth TJ, Marchant R (2010) Microbial biosurfactants production, applications and future potential. Appl Microbiol Biotechnol 87: 427-444. https://doi.org/10.1007/s00253-010-2589-0

Bergstrom S, Theorell H, Davide H (1946) Pyolipic acid, a metabolic product of Pseudomonas pyocyanea, active against Mycobacterium tuberculosis. Arch Biochem 10:165-166

Bubb WA (2003) NMR spectroscopy in the study of carbohydrates: characterizing the structural complexity. Concepts Magn Reson Part A Bridg Educ Res 19:1-19. https://doi.org/10.1002/cmr.a.10080

Cabrera-Valladares N, Richardson AP, Olvera C, Treviño LG, Déziel E, Lépine F, Soberón-Chávez G (2006) Monorhamnolipids and 3-(3hydroxyalkanoyloxy) alkanoic acids (HAAs) production using Escherichia coli as a heterologous host. Appl Microbiol Biotechnol 73:187-194. https://doi.org/10.1007/s00253-006-0468-5

Chen J, Sun J, Deering RW, Dasilva N, Seeram NP, Wang H, Rowley DC (2016) Rhizoleucinoside, a Rhamnolipid-amino alcohol hybrid from the Rhizobial symbiont Bradyrhizobium sp. BTAil. Org Lett 18: 1490-1493. https://doi.org/10.1021/acs.orglett.6b00461

Desai JD, Banat IM (1997) Microbial production of surfactants and their commercial potential. Microbiol Mol Biol Rev 61:47-64. https:// doi.org/10.1016/S0140-6701(97)84559-6

Déziel E, Lépine F, Dennie D, Boismenu D, Mamer OA, Villemur R (1999) Liquid chromatography/mass spectrometry analysis of mixtures of rhamnolipids produced by Pseudomonas aeruginosa strain 57RP grown on mannitol or naphthalene. Biochim Biophys Acta Mol Cell Biol Lipids 1440:244-252. https://doi.org/10.1016/S13881981(99)00129-8

Deziel E, Lepine F, Milot S, Villemur R (2003) rhlA is required for the production of a novel biosurfactant promoting swarming motility in Pseudomonas aeruginosa: 3-(3-hydroxyalkanoyloxy)alkanoic acids (HAAs), the precursors of rhamnolipids. Microbiology 149:20052013. https://doi.org/10.1099/mic.0.26154-0

Dreja M, Vockenroth I, Plath N (2012) Biosurfactants - exotic specialties or ready for application? Tenside Surfactants Deterg 49:10-17. https://doi.org/10.3139/113.110158

Dubeau D, Déziel E, Woods DE, Lépine F (2009) Burkholderia thailandensis harbors two identical $r h l$ gene clusters responsible for the biosynthesis of rhamnolipids. BMC Microbiol 9:263. https://doi.org/10.1186/1471-2180-9-263

Dyksterhouse SE, Gray JP, Herwig RP, Lara JC, Staley JT (1995) Cycloclasticus pugetii gen. Nov., sp. nov., an aromatic hydrocarbon-degrading bacterium from marine sediments. Int J Syst Bacteriol 45:116-123. https://doi.org/10.1099/00207713-45-1-116

Elshikh M, Funston S, Chebbi A, Ahmed S, Marchant R, Banat IM (2017) Rhamnolipids from non-pathogenic Burkholderia thailandensis E264: physicochemical characterization, antimicrobial and antibiofilm efficacy against oral hygiene related pathogens. New Biotechnol 36:26-36. https://doi.org/10.1016/j.nbt.2016.12. 009

Faccone D, Pasteran F, Albornoz E, Gonzalez L, Veliz O, Prieto M, Bucciarelli R, Callejo R, Corso A (2014) Human infections due to Pseudomonas chlororaphis and Pseudomonas oleovorans harboring new blaVIM-2-borne integrons. Infect Genet Evol 28:276-277. https://doi.org/10.1016/j.meegid.2014.10.012

Franzetti A, Gandolfi I, Raimondi C, Bestetti G, Banat IM, Smyth TJ, Papacchini M, Cavallo M, Fracchia L (2012) Environmental fate, toxicity, characteristics and potential applications of novel bioemulsifiers produced by Variovorax paradoxus $7 \mathrm{bCT} 5$. Bioresour Technol 108:245-251. https://doi.org/10.1016/j.biortech. 2012.01.005

Funston SJ, Tsaousi K, Smyth TJ, Twigg MS, Marchant R, Banat Ibrahim M (2017) Enhanced rhamnolipid production in Burkholderia thailandensis transposon knockout strains deficient in polyhydroxyalkanoate ( PHA ) synthesis. Appl Microbiol Biotechnol. https://doi.org/10.1007/s00253-017-8540-x 
Funston SJ, Tsaousi K, Rudden M, Smyth TJ, Stevenson PS, Marchant R, Banat IM (2016) Characterising rhamnolipid production in Burkholderia thailandensis E264, a non-pathogenic producer. Appl Microbiol Biotechnol 100:7945-7956. https://doi.org/10. 1007/s00253-016-7564-y

Gautam L, Kaur R, Kumar S, Bansal A, Gautam V, Singh M, Ray P (2015) Pseudomonas oleovorans sepsis in a child: the first reported case in India. Jpn J Infect Dis 68:254-255. https://doi.org/10.7883/ yoken.JJID.2014.174

Gomila M, Peña A, Mulet M, Lalucat J, García-Valdés E (2015) Phylogenomics and systematics in Pseudomonas. Front Microbiol 6:1-13. https://doi.org/10.3389/fmicb.2015.00214

Green DH, Bowman JP, Smith EA, Gutierrez T, Bolch CJS (2006) Marinobacter algicola $s p$. nov., isolated from laboratory cultures of paralytic shellfish toxin-producing dinoflagellates. Int J Syst Evol Microbiol 56:523-527. https://doi.org/10.1099/ijs.0.63447-0

Green DH, Llewellyn LE, Negri AP, Blackburn SI, Bolch CJS (2004) Phylogenetic and functional diversity of the cultivable bacterial community associated with the paralytic shellfish poisoning dinoflagellate Gymnodinium catenatum. FEMS Microbiol Ecol 47:345357. https://doi.org/10.1016/S0168-6496(03)00298-8

Grosso-Becerra MV, González-Valdez A, Granados-Martínez MJ, Morales E, Servín-González L, Méndez JL, Delgado G, MoralesEspinosa R, Ponce-Soto GY, Cocotl-Yañez M, Soberón-Chávez G (2016) Pseudomonas aeruginosa ATCC 9027 is a non-virulent strain suitable for mono-rhamnolipids production. Appl Microbiol Biotechnol 100:9995-10004. https://doi.org/10.1007/s00253-0167789-9

Gunther NW, Nunez A, Fett W, Solaiman DKY (2005) Production of Rhamnolipids by Pseudomonas chlororaphis, a nonpathogenic bacterium. Appl Environ Microbiol 71:2288-2293. https://doi.org/10. 1128/AEM.71.5.2288

Gutierrez T, Green DH, Nichols PD, Whitman WB, Semple KT, Aitken MD (2013) Polycyclovorans algicola gen. Nov., sp. nov., an aromatic-hydrocarbon- degrading marine bacterium found associated with laboratory cultures of marine phytoplankton. Appl Environ Microbiol 79:205-214. https://doi.org/10.1128/AEM.02833-12

Gutierrez T, Green DH, Whitman WB, Nichols PD, Semple KT, Aitken MD (2012a) Algiphilus aromaticivorans gen. Nov., sp. nov., an aromatic hydrocarbon-degrading bacterium isolated from a culture of the marine dinoflagellate Lingulodinium polyedrum, and proposal of Algiphilaceae fam. Nov. Int J Syst Evol Microbiol 62:2743-2749. https://doi.org/10.1099/ijs.0.033324-0

Gutierrez T, Nichols PD, Whitman WB, Aitken MD (2012b) Porticoccus hydrocarbonoclasticus sp. nov., an aromatic hydrocarbon-degrading bacterium identified in laboratory cultures of marine phytoplankton. Appl Environ Microbiol 78:628-637. https://doi.org/10.1128/AEM. 06398-11

Gutierrez T, Rhodes G, Mishamandani S, Berry D, Whitman WB, Nichols PD, Semple KT, Aitken MD (2014) Polycyclic aromatic hydrocarbon degradation of phytoplankton-associated Arenibacter spp. and description of Arenibacter algicola sp. nov., an aromatic hydrocarbon-degrading bacterium. Appl Environ Microbiol 80: 618-628. https://doi.org/10.1128/AEM.03104-13

Gutierrez T, Singleton DR, Aitken MD, Semple KT (2011) Stable isotope probing of an algal bloom to identify uncultivated members of the Rhodobacteraceae associated with low-molecular-weight polycyclic aromatic hydrocarbon degradation. Appl Environ Microbiol 77:7856-7860. https://doi.org/10.1128/AEM.06200-11

Hill L, Veli N, Coote PJ (2014) Evaluation of Galleria mellonella larvae for measuring the efficacy and pharmacokinetics of antibiotic therapies against Pseudomonas aeruginosa infection. Int $\mathrm{J}$ Antimicrob Agents 43:254-261. https://doi.org/10.1016/j.ijantimicag.2013.11. 001

Irorere VU, Tripathi L, Marchant R, McClean S, Banat IM (2017) Microbial rhamnolipid production: a critical re-evaluation of published data and suggested future publication criteria. Appl Microbiol Biotechnol 101:3941-3951. https://doi.org/10.1007/ s00253-017-8262-0

Ismail W, Al SS, El-Sayed WS, Obuekwe C, El Nayal AM, Abdul Raheem AS, Al-Humam A (2015) Stimulation of rhamnolipid biosurfactants production in Pseudomonas aeruginosa AK6U by organosulfur compounds provided as sulfur sources. Biotechnol Reports 7:55-63. https://doi.org/10.1016/j.btre.2015.03.001

Jarvis FG, Johnson MJ (1949) A Glyco-lipid produced by Pseudomonas aeruginosa. J Am Chem Soc 71:4124-4126. https://doi.org/10. 1021/ja01180a073

Jensen P, Bjarnsholt T, Phipps R, Rasmussen TB, Calum H, Christoffersen L, Moser C, Williams P, Pressler T, Givskov M, Høiby N (2007) Rapid necrotic killing of polymorphonuclear leukocytes is caused by quorum-sensing-controlled production of rhamnolipid by Pseudomonas aeruginosa. Microbiology 153: 1329-1338. https://doi.org/10.1099/mic.0.2006/003863-0

Johansen HK, Kjeldsen K, Høiby N (2001) Pseudomonas mendocina as a cause of chronic infective endocarditis in a patient with situs inversus. Clin Microbiol Infect 7:650-652. https://doi.org/10.1046/ j.1198-743x.2001.00331.x

Kiyohara H, Nagao K, Yana K (1982) Rapid screen for Bacteria degrading water-insoluble. Solid Hydrocarbons on Agar Plates Appl Environ Microbiol 43:454-457

Kügler JH, Muhle-Goll C, Kühl B, Kraft A, Heinzler R, Kirschhöfer F, Henkel M, Wray V, Luy B, Brenner-Weiss G, Lang S, Syldatk C, Hausmann R (2014) Trehalose lipid biosurfactants produced by the actinomycetes Tsukamurella spumae and T. pseudospumae. Appl Microbiol Biotechnol 98:8905-8915. https://doi.org/10.1007/ s00253-014-5972-4

Laboratory CSH (2012) Artificial seawater. Cold spring Harb Protoc 2012:pdb.rec068270. doi: https://doi.org/10.1101/pdb.rec068270

Mangwani N, Shukla SK, Rao TS, Das S (2014) Calcium-mediated modulation of Pseudomonas mendocina NR802 biofilm influences the phenanthrene degradation. Colloids Surfaces B Biointerfaces 114: 301-309. https://doi.org/10.1016/j.colsurfb.2013.10.003

Marchant R, Banat IM (2014) Protocols for measuring biosurfactant production in microbial cultures. In: McGenity TJ, Timmis KN, Nogales B (eds) Hydrocarbon and lipid microbiology protocols: activities and phenotypes. Springer Berlin Heidelberg, Berlin, Heidelberg, pp 119-128

Marchant R, Banat IM (2012) Biosurfactants: a sustainable replacement for chemical surfactants? Biotechnol Lett 34:1597-1605. https://doi. org/10.1007/s10529-012-0956-x

Martinez-Toledo A, Rios-Leal E, Vazquez-Duhalt R, del GonzalezChavez MC, Esparza-Garcia JF, Rodriguez-Vazquez R (2006) Role of phenanthrene in rhamnolipid production by $P$. putida in different media. Environ Technol 27:137-142. https://doi.org/10. 1080/09593332708618628

Mishamandani S, Gutierrez T, Berry D, Aitken MD (2016) Response of the bacterial community associated with a cosmopolitan marine diatom to crude oil shows a preference for the biodegradation of aromatic hydrocarbons. Environ Microbiol 18:1817-1833. https://doi. org/10.1111/1462-2920.12988

Mukherjee K, Domann E, Hain T (2011) In: Vilcinskas A (ed) The greater wax moth Galleria mellonella as an alternative model host for human pathogens BT - insect biotechnology. Springer Netherlands, Dordrecht, pp 3-14

Nordin N, Zakaria MR, Halmi MIE, Ariff A, Zawawi RM, Wasoh H (2013) Isolation and screening of high efficiency biosurfactant-producing Pseudomonas sp. J Biochem Microbiol Biotechnol 1:25-31

Ochsner UA, Fiechter A, Reiser J (1994) Isolation, characterization, and expression in Escherichia coli of the Pseudomonas aeruginosa rhlAB genes encoding a rhamnosyltransferase involved in rhamnolipid biosurfactant synthesis. J Biol Chem 269:19787-19795 
Pearson JP, Pesci EC, Iglewski BH (1997) Roles of Pseudomonas aeruginosa las and rhl quorum-sensing systems in control of elastase and rhamnolipid biosynthesis genes. J Bacteriol 179:57565767. https://doi.org/10.1128/JB.179.18.5756-5767.1997

Rahim R, Ochsner UA, Olvera C, Graninger M, Messner P, Lam JS, Soberon-Chavez G (2001) Cloning and functional characterization of the Pseudomonas aeruginosa rhlC gene that encodes rhamnosyltransferase 2, an enzyme responsible for di-rhamnolipid biosynthesis. Mol Microbiol 40:708-718

Rudden M, Tsaousi K, Marchant R, Banat IM, Smyth TJ (2015) Development and validation of an ultra-performance liquid chromatography tandem mass spectrometry (UPLC-MS/MS) method for the quantitative determination of rhamnolipid congeners. Appl Microbiol Biotechnol 99:9177-9187. https://doi.org/10.1007/ s00253-015-6837-1

Saha R, Spröer C, Beck B, Bagley S (2010) Pseudomonas oleovorans subsp. lubricantis subsp. nov., and reclassification of Pseudomonas pseudoalcaligenes ATCC $17440 \mathrm{~T}$ as later synonym of Pseudomonas oleovorans ATCC 8062T. Curr Microbiol 60:294 300. https://doi.org/10.1007/s00284-009-9540-6

Sambrook J, Russell DW (2001) Molecular cloning a laboratory manual. Cold Spring Harbor laboratory press, Cold Spring Harbor, N.Y

Shi S, Tang D, Liu Y (2009) Effects of an algicidal bacterium Pseudomonas mendocina on the growth and antioxidant system of Aphanizomenon flos-aquae. Curr Microbiol 59:107-112. https:// doi.org/10.1007/s00284-009-9404-0

Soberón-Chávez G, Lépine F, Déziel E (2005) Production of rhamnolipids by Pseudomonas aeruginosa. Appl Microbiol Biotechnol 68:718-725. https://doi.org/10.1007/s00253-005-0150-3

Stover CK, Pham XQ, Erwin AL, Mizoguchi SD, Warrener P, Hickey MJ, Brinkman FSL, Hufnagle WO, Kowallk DJ, Lagrou M, Garber RL, Goltry L, Tolentino E, Westbrock-Wadman S, Yuan Y, Brody LL, Coulter SN, Folger KR, Kas A, Larbig K, Lim R, Smith K, Spencer D, Wong GKS, Wu Z, Paulsen IT, Relzer J, Saler MH, Hancock REW, Lory S, Olson MV (2000) Complete genome sequence of Pseudomonas aeruginosa PAO1, an opportunistic pathogen. Nature 406:959-964. https://doi.org/10.1038/35023079
Tedesco P, Maida I, Esposito FP, Tortorella E, Subko K, Ezeofor CC, Zhang Y, Tabudravu J, Jaspars M, Fani R, De Pascale D (2016) Antimicrobial activity of monoramnholipids produced by bacterial strains isolated from the Ross Sea (Antarctica). Mar Drugs 14. https://doi.org/10.3390/md14050083

Thompson H, Angelova A, Bowler B, Jones M, Gutierrez T (2017) Enhanced crude oil biodegradative potential of natural phytoplankton-associated hydrocarbonoclastic bacteria. Environ Microbiol 19: 2843-2861. https://doi.org/10.1111/1462-2920.13811

Tsai CJ-Y, Loh JMS, Proft T (2016) Galleria mellonella infection models for the study of bacterial diseases and for antimicrobial drug testing. Virulence 7:214-229. https://doi.org/10.1080/21505594.2015. 1135289

Vasileva-Tonkova E, Galabova D, Stoimenova E, Lalchev Z (2006) Production and properties of biosurfactants from a newly isolated Pseudomonas fluorescens HW-6 growing on hexadecane. Z Naturforsch C 61:553-559

Vasileva-Tonkova E, Sotirova A, Galabova D (2011) The effect of rhamnolipid biosurfactant produced by Pseudomonas fluorescens on model bacterial strains and isolates from industrial wastewater. Curr Microbiol 62(2):427-433

Wittgens A, Tiso T, Arndt TT, Wenk P, Hemmerich J, Müller C, Wichmann R, Küpper B, Zwick M, Wilhelm S, Hausmann R, Syldatk C, Rosenau F, Blank LM (2011) Growth independent rhamnolipid production from glucose using the non-pathogenic Pseudomonas putida KT2440. Microb Cell Factories 10:80. https://doi.org/10.1186/1475-2859-10-80

Xu J, Qiu X, Dai J, Cao H, Yang M, Zhang J, Xu M (2006) Isolation and characterization of a Pseudomonas oleovorans degrading the chloroacetamide herbicide acetochlor. Biodegradation 17:219-225. https://doi.org/10.1007/s10532-005-4220-0

Zhu K, Rock CO (2008) RhlA converts $\beta$-hydroxyacyl-acyl carrier protein intermediates in fatty acid synthesis to the $\beta$-hydroxydecanoyl$\beta$-hydroxydecanoate component of rhamnolipids in Pseudomonas aeruginosa. J Bacteriol 190:3147-3154. https://doi.org/10.1128/JB. 00080-08

Zobell CE (1941) Studies on marine Bacteria. I. The cultural requirements of heterotrophic aerobes. J Mar Res 4:42-45 